\title{
GERAÇÃO DO MORRO: RELATO DE UM PROJETO DE INTERVENÇÃO PSICOEDUCATIVA EM UMA ESCOLA PÚBLICA
}

\author{
Luciana Szymanski ${ }^{1}$ \\ Isabel Santana Gervitz ${ }^{2}$ \\ Luiza Capucci ${ }^{3}$
}

\begin{abstract}
Resumo
O artigo propõe a análise de uma intervenção psicoeducativa realizada em uma escola pública de São Paulo. A escola pediu implementação de um projeto que desse voz ao coletivo de alunos, sistematizasse suas queixas e aspirações e construísse caminhos de solução para as dificuldades. A proposta dialógica de Paulo Freire e a perspectiva fenomenológica embasaram teoricamente as ações e análises desenvolvidas. Realizaram-se atividades grupais e encontros reflexivos, cuja análise evidenciou que os alunos podiam ser participantes ativos dentro do coletivo da escola. O projeto incluiu o educador, buscando ferramentas que o fortalecia em seu papel, e reverberou-se em outros espaços, como o da família. Após seu término, a escola solicitou sua continuidade, garantindo, na instituição, a presença do psicólogo em formação além da discussão sobre a inserção desse profissional no cotidiano escolar. Em última instância, o projeto contribuiu para uma aproximação entre a Universidade e Comunidade.
\end{abstract}

Palavras-chave: Práticas Psicoeducativas; Formação do Psicólogo; Fenomenologia; Práticas Psicológicas

\footnotetext{
${ }^{1}$ Doutorado em Educação (Psicologia da Educação) pela Pontifícia Universidade Católica de São Paulo, Brasil(2006). Endereço: Rua Monte Alegre 984, Perdizes. São Paulo. 05014-901 - FACHS Endereço eletrônico: lucianaszymanski@gmail.com

${ }^{2}$ Psicóloga - PUC- SP. Endereço: Rua Monte Alegre 984, Perdizes. São Paulo. 05014-901 - FACHS Endereço eletrônico: belgervitz@ hotmail.com

${ }^{3}$ Psicóloga - PUC-SP. Endereço: Rua Monte Alegre 984, Perdizes. São Paulo. 05014-901 - FACHS Endereço eletrônico: lulucapucci@gmail.com
} 


\title{
1 APRESENTAÇÃO: PERCORRENDO OS PASSOS RUMO A UMA INTERVENÇÃO INSTITUCIONAL
}

\begin{abstract}
Não, não era para irritar o professor que eu não estudava; só tinha tempo de crescer. $\mathrm{O}$ que eu fazia para todos os lados, com uma falta de graça que mais parecia o resultado de um erro de cálculo: as pernas não combinavam com os olhos, e a boca era emocionada enquanto as mãos se esgalhavam sujas — na minha pressa eu crescia sem saber para onde. (LISPECTOR, 1992. p. 12).
\end{abstract}

O presente artigo tem por objetivo descrever uma intervenção psicoeducativa realizada no decorrer do ano de 2013 em uma Escola Municipal de Ensino Fundamental localizada na região da Brasilândia/Freguesia do Ó, Zona Norte da cidade de São Paulo. A intervenção deuse em um estágio supervisionado de formação realizado pelas alunas de quinto e último ano do curso de Psicologia, no âmbito de um projeto mais amplo de intervenção coordenado pela docente supervisora (SZYMANSKI et al., 2011).

Após a apresentação das estagiárias à equipe gestora da escola, realizou-se o primeiro momento do estágio com o objetivo de situar-se no espaço de atuação, de conhecer/reconhecer a ocupação do território, mapear os equipamentos da escola e ouvir as experiências das pessoas nas diversas instâncias institucionais (professores, gestores, crianças). Este foi o momento de reconhecimento territorial que marcou o início do estágio em que se delineou uma cartografia ${ }^{4}$ do lugar a ser compartilhado com aqueles que nele habitam. Neste primeiro reconhecimento, o entorno da escola também seria visitado.

O momento seguinte consistiu em delinear a demanda. O léxico nos informa que demanda refere-se à "manifestação de um desejo, pedido ou exigência; solicitação, necessidade premente de; carecimento, precisão; ação de procurar alguma coisa; busca diligência (...) pergunta; interrogação, indagação" (HOUAISS, 2001, p. 933). Note-se que o significado da palavra inclui: necessidade de algo, interrogação, pedido e busca. Definir a demanda requer, portanto, experiência e compreensão prévias, advindas da imersão no território em que realizar-se-ão a intervenção psicoeducativa e o encontro com aqueles que a solicitaram. Nesse encontro a interrogação pelo sentido da demanda, a percepção da necessidade e do pedido e os caminhos de busca de compreensão e solução da crise, da ruptura ou da desestabilização serão gradativamente esclarecidos. Para Morato (1999) a demanda pode ser compreendida como a urgência por atenção psicológica cujo sentido será

\footnotetext{
${ }^{4}$ Entendida não só como a descrição do espaço geográfico, mas também a do espaço vivido pelo cartógrafo e pelas pessoas que o habitam, incluindo como o compreendem, como são afetados por ele, como o dividem com os outros que lá estão presentes.
} 
construído na investigação da situação de crise. No presente caso, será proposto um projeto de atenção psicoeducativa que resultou do processo de esclarecimento da demanda.

Após encontro com a equipe gestora da EMEF percebeu-se que a demanda estava relacionada com modos de agir de alunos que se encaminhavam para os anos finais do Ensino Fundamental, atribuídos pelos gestores ao estranhamento diante de uma nova estrutura curricular e expressos como: desinteresse, apatia, agressividade, agitação e inadequação na sala de aula. Durante a reunião, a coordenadora e professoras levantaram também como hipóteses que poderiam explicar tais procedimentos dos alunos: complicada situação socioeconômica e familiar de alguns alunos, uma desesperança e um imediatismo derivados dessas vivências difíceis. Tentaram, entretanto, evitar uma "vitimização" dos alunos, lembrando suas possibilidades de superação.

Após o encontro com a equipe, em que se levantou essa problemática em relação ao grupo de crianças que se movimentava em direção ao Fundamental II, o estágio passou para seu terceiro momento, caracterizado por uma imersão no cotidiano da escola, o conhecimento do prédio e seu funcionamento, sua rotina e o diálogo com educadores, funcionários, crianças, pais e gestores da instituição educacional.

Esse período teve a duração de aproximadamente um mês, e desembocou no passo seguinte, o quarto momento do estágio, aqui caracterizado como o momento da construção de um plano de intervenção que respondesse às demandas institucionais desenhadas até então. Nesse momento ficou claro que os objetivos da escola e do estágio estavam alinhados com e buscavam compreender as necessidades dos educandos em relação à escola, seu olhar, suas queixas ou, nas palavras da escola, seu "grito"5. Assim, ficou entendido que deveria ser desenvolvido ao longo do ano o trabalho com grupos específicos de crianças de 9 a 10 anos (vivendo o ingresso nos anos finais do Ensino Fundamental, uma transição importante na vida escolar). A demanda que se configurou nesse momento foi: Como compreender os modos de agir das crianças que se encaminhavam para os anos finais do Ensino Fundamental e que ações empreender para solucionar as dificuldades que surgiam em relação aos alunos, em decorrência do desinteresse, apatia, agressividade, agitação e inadequação na sala de aula, acarretando consequências no seu aproveitamento acadêmico e relações interpessoais?

\footnotetext{
${ }^{5}$ O termo grito é utilizado por Fernando Colli (em palestra de 2013 a educadores da rede municipal de ensino de São Paulo) como sendo algo da ordem do biológico que não pode ser transposto em palavras. Este aspecto da vivência, por ser angustiante, impulsiona o ser humano a buscar o conhecimento, na tentativa de compreendê-la.
} 
O momento seguinte foi a construção de um plano de intervenção voltado para esse grupo de alunos e sua relação com as demais instâncias institucionais. Deu-se início ao projeto que foi denominado como "Geração do Morro", numa alusão ao bairro que leva o mesmo nome.

O objetivo do projeto foi dar voz ao coletivo de alunos a partir de uma sistematização das suas queixas e vivências manifestadas nas atividades que seriam realizadas com eles durante a intervenção e construir conjuntamente caminhos de solução das dificuldades relatadas nas queixas. Nosso objetivo, ao divulgar essa experiência, é o de compartilhar, passo a passo, a compreensão e tradução dos desejos de um grupo de alunos, educadores e gestores e a transformação desse desejo em possiblidades de ações, a partir de um olhar e escuta apurados praticados ao longo de um estágio de Psicologia.

\section{BREVE REFERÊNCIA À ORIENTAÇÃO TEÓRICA}

O pensamento de Paulo Freire atravessa a proposta de intervenção psicoeducativa, tanto no aspecto teórico como nas práticas desenvolvidas, tendo como eixo seu pensamento que propõe uma “(...) prática educativo-progressiva em favor da autonomia do ser dos educandos (...)” (FREIRE, 1996, p. 14). Freire tem no diálogo uma condição fundamental para uma educação e projeto pedagógico atravessado pelo que ele chama de "responsabilidade ética no exercício de nossa tarefa docente. [...] a Ética de que falo é a que se sabe afrontada na manifestação discriminatória de raça, de gênero, de classe” (idem, p. 16-17). Para Zitkoski (2010) o diálogo na perspectiva freireana “(...) é a força que impulsiona o pensar críticoproblematizador em relação à condição humana no mundo" (p. 117).

Um dos aspectos enfatizados por Freire, referindo-se ao ensinar, mas que adotamos como premissa para nosso trabalho é o da corporificação das palavras pelo exemplo, o que vale dizer que a postura dialógica acompanha todos os momentos da intervenção psicoeducativa.

Um dos aspectos essenciais do diálogo é o saber ouvir, a escuta atenta e respeitosa, na consideração pelo interlocutor numa relação horizontal "em que a confiança de um polo no outro é consequência óbvia" (FREIRE, 1987, p. 81), além da consideração do outro como um sujeito de igual valor humano. 
Diferentemente do que o senso comum imagina, não é o falar o aspecto mais importante do diálogo. Este só se completa com a presença de uma escuta ativa, que implica respeito, como vimos acima, atenção e um processo de construção de uma compreensão continuamente partilhada com o outro. Diz Freire (1998) que, "No processo da fala e da escuta, a disciplina do silêncio a ser assumido com rigor e a seu tempo pelos sujeitos que falam e escutam é um 'sine qua non’ da comunicação dialógica” (p. 131).

Isso não significa que não haja diferenças entre pontos de vista e interpretações, mas o que caracteriza um encontro dialógico é a intencionalidade de chegar-se a um consenso.

Podemos fazer um paralelo entre a posição defendida acima por Freire e a explanação de Gadamer (2002) a respeito da conversação. Para esse autor,

A conversação é um processo pelo qual se procura chegar a um acordo. Faz parte de toda verdadeira conversação atender realmente ao outro, deixar valer os seus pontos de vista e pôr-se no seu lugar, e talvez não no sentido de que se queira entendê-lo como esta individualidade, mas sim no que se procura entender o que diz. (p. 561)

$\mathrm{Na}$ afirmação acima, o foco está na compreensão e na atividade de pensar, que para Arendt (2002) significa “desgelar" ideias e conceitos a fim de chegar à sua compreensão, que “(...) a linguagem, veículo do pensamento, congelou como pensamentos-palavras (conceitos, frases, definições, doutrinas) (...)" (p. 131). No diálogo, a busca de compreender o ponto de vista do outro e expressar o próprio pensamento focaliza-se na compreensão de um tema, de uma ideia, de um problema, com a finalidade de chegar a uma posição comum. Para isso ambas as partes que dialogam devem estar dispostas a descongelar ideias pré-concebidas, atitudes arraigadas e modos de agir cristalizados.

\subsection{Algumas considerações sobre o que entendemos por intervenção psicoeducativa}

O termo intervenção pode ter à primeira vista apenas uma conotação autoritária, impositiva, mas o dicionário nos aponta outros significados, entre eles: "ingerência de um indivíduo ou instituição em negócios de outrem, como intercessor, mediador etc.; em um debate, discussão, sessão, etc., ato de emitir opinião, contribuir com ideias, estar presente" (HOUAISS, 2001, p. 1637). Intervir tem tanto o sentido de interpor autoridade como poder; tanto de influir numa questão como de impedir algo; tanto de interceder como de impor 
limites ou a lei. O significado do termo desvela diferentes intenções: tanto a de imposição como a de interpor os bons ofícios. Deve ser explicitado que uma intervenção de caráter dialógico e participativo como a nossa não se coaduna com práticas autoritárias, o que significa que ficamos com a segunda conotação acima.

Intervenções psicoeducativas

\begin{abstract}
envolvem ações reflexivas [...] de caráter psicológico e educacional, desenvolvidas por profissionais junto a uma comunidade ou instituição de educação formal ou informal, com a finalidade de atender a demandas de educadores, pais, gestores e demais protagonistas do cenário educacional. (SZYMANSKI; SZYMANSKI, 2013, p. 77).
\end{abstract}

Uma intervenção psicoeducativa inclui práticas reflexivas que têm base na conversação dialógica, na qual a reflexão se coloca como ação que possibilita a troca contínua de compreensão entre os interlocutores, de forma que todos possam também ouvir sua fala tal como foi compreendida pelo outro, além de reconsiderar suas próprias ideias. Refletir, refletir, fletir, curvar-se novamente sobre o ouvido e o pensado. A reflexividade das práticas busca tanto a compreensão como a horizontalidade e igualdade de valor humano entre os protagonistas.

\title{
3 ALGUMAS CONSIDERAÇÕES METODOLÓGICAS ACERCA DOS PROCEDIMENTOS DE INTERVENÇÃO
}

Como foi apontado, tanto no reconhecimento territorial quanto no terceiro momento de imersão no cotidiano da escola -, orientamo-nos pelos princípios básicos da observação participante, que propõe um tempo de convivência entre pesquisadores/profissionais e participantes para que possam apreender alguns aspectos da "cultura" do local em que vão pesquisar/trabalhar a partir de um olhar atento para o desenrolar do cotidiano. A observação participante tem suas origens na etnometodologia, desenvolvida, primeiramente, em pesquisas na área de Antropologia, mas, como lembra Minayo (2010), "não tem a pretensão de produzir análises culturais" (p. 149). Thiollent (1999) ressalta que a observação participante tem a finalidade de "diminuir a estranheza entre os participantes e pesquisadores" (p. 83).

Para o planejamento das atividades houve a preocupação de lançar mão de uma prática psicoeducativa que estivesse de acordo com os princípios da proposta dialógica de Paulo Freire, com um caráter participativo e reflexivo. O encontro reflexivo preenchia essas 
condições. "O encontro reflexivo é uma prática de que se pode lançar mão sempre que houver uma demanda de um grupo de pessoas que desejam buscar soluções e alternativas para questões comuns e significativas de sua existência” SZYMANSKI; SZYMANSKI, 2014, p. 12). Uma característica importante do encontro reflexivo é a utilização de atividades vivenciais relacionadas ao problema em questão, seguidas sempre de reflexão e explicitação da compreensão possibilitada pela atividade.

A possibilidade de trocas interpessoais em situações grupais como as propostas durante os encontros reflexivos permite que se desenvolva não só uma compreensão multifacetada daquilo que queremos entender, como possibilita uma relação de colaboração entre os participantes. Aí reside a importância e riqueza do trabalho em grupo, em que um participante é provocado por outro, sintetiza a fala dos anteriores, repensa suas colocações, até que ideias coletivas conferem àquele grupo uma identidade própria, soluções próprias e um perfil próprio.

O grupo oferece um ambiente propício para se narrarem experiências, ouvir, a si mesmo, ao outro, de reconhecer o impacto das próprias ideias no outro, entre pessoas que vivem situações semelhantes. Em um encontro grupal, a interação favorece a lembrança, reinterpretações, comparações e o resultado é uma produção conjunta, uma criação. (SZYMANSKI; SZYMANSKI, 2014, p. 12)

Quanto à análise dos registros de observação, seguiram-se procedimentos adotados pela metodologia da pesquisa qualitativa, de base fenomenológica, que busca “(...) uma compreensão particular daquilo que se estuda [...] almejando sempre a compreensão e não a explicação dos fenômenos estudados" (MARTINS; BICUDO, 2005, p. 23). Segundo a perspectiva hermenêutica a compreensão se revela quando se responde ao sentido que se desvela após a imersão no texto. Entende-se por sentido o destino, o rumo e a direção (CRITELLI, 1996), em outras palavras, a resposta à indagação do "para quê" do fenômeno que se desvelou a partir da observação e descrição. 


\section{A IMPLEMENTAÇÃO DA INTERVENÇÃO}

\subsection{A Escola}

A EMEF - Escola Municipal de Ensino Fundamental, aqui denominada como Geração do Morro - foi construída em 2009 e conta com o mesmo diretor desde então. Atende alunos do primeiro ao nono ano. É digna de nota a preocupação em manter a escola muito bem cuidada, com plantas, árvores, móveis bem conservados, quadra coberta (conseguida com muita luta), ambientes de leitura no pátio coberto de recreio, trabalhos das aulas de Artes expostos, sala de informática com plena utilização, biblioteca sempre alimentada com novos livros, bem como o fato de os alunos terem uma relação próxima e afetiva com o diretor. A escola se encontra em um bairro da Zona Norte, afastado do Centro que, nos últimos anos, com a melhoria de renda da população local, tem apenas casas de alvenaria, algumas com bastante conforto, além de serviços de água, esgoto, iluminação, transporte. Há, entretanto, focos de violência, atravessamento do tráfico, embora a escola nunca tenha sofrido agressão direta.

A EMEF caracteriza-se por duas grandes condições: abertura para a comunidade e gestão participativa. Quanto à primeira, desenvolveram-se parcerias com várias instituições formais e não formais do bairro: a Escola de Samba do bairro, que faz seus ensaios na quadra da escola (durante os quais o consumo de álcool obviamente é proibido) e treina a fanfarra da escola; a Passeata pela Paz (em conjunto com o projeto Criança, Esperança); a Mostra de Ciência e Cultura nas ruas da comunidade e dentro da escola; a Parceria com PUC-SP. Estas e muitas outras ações inserem a escola na comunidade e vice-versa.

Quanto à gestão participativa, pode-se lembrar que "está associada à mobilização de talentos e esforços coletivamente organizados, à ação construtiva conjunta de seus componentes, pelo trabalho associado, mediante reciprocidade que cria um 'todo' orientado por uma vontade coletiva" (LÜCK et al., 2005, p. 17). Na EMEF Geração do Morro todas as decisões são discutidas pela equipe gestora, composta pelo diretor, vice-diretora e coordenadoras pedagógicas. O Conselho de Escola tem a participação efetiva de representantes de todos os segmentos (alunos, professores, funcionários, famílias); a Associação de Pais e Mestres é ativa, e a presença de representantes da comunidade é sempre bem-vinda na escola. 


\subsection{Os Alunos Participantes}

A escolha dos grupos de crianças, contemplados nesse estágio, foi feita de forma que eles tivessem característica heterogênea, para fugir à estigmatização daquele que "sai da sala de aula", como sendo visto pela maioria como o responsável pela bagunça, "mau-aluno", ou que precisa do psicólogo por razões de "problemas individuais". A possibilidade de ser reconhecido por outros aspectos que não os ditos problemáticos abre oportunidades de expressão e reconhecimento para todos os participantes.

Formaram-se agrupamentos representativos de cada classe, abrangendo a maior variedade possível de salas e alunos, desde que eles mostrassem interesse em participar. Havia alunos de 9 e 10 anos e procurou-se formar grupos que incluíssem meninos e meninas. Esses grupos mantiveram-se os mesmos e participaram dos encontros até o final do projeto. No total participaram 60 crianças mais diretamente, em grupos de 8 ou 9, sendo número equilibrado de meninos e meninas.

\subsection{Ações de Intervenções e suas Repercussões}

O planejamento das atividades, estruturado semanalmente e considerando-se o que fora observado e vivenciado no encontro anterior, era apresentado aos professores e gestores, de modo que sempre houve abertura para sugestões, dúvidas e novas colaborações de qualquer instância institucional. Havia, em todas as atividades planejadas, uma discussão sistemática com os alunos, por meio de atividades lúdicas, que trouxe à tona os descontentamentos e as possibilidades de ação. Devolutivas mensais foram dadas aos educadores e gestores a respeito do que fora observado e novas atividades grupais criadas para que a voz dessas crianças fosse ouvida por todos.

Ao longo da realização do trabalho ocorreu uma diversidade de possibilidades de modos expressivos, como fala, desenho, escrita, colagem e pintura. Desse modo, os alunos puderam encontrar formas diferentes de se expressarem, que talvez não pudessem ser percebidas em sala de aula. Notamos que um menino que normalmente não se concentrava em atividades de discussão ficou extremamente compenetrado desenhando e orgulhoso do resultado de seu 
trabalho. A todo momento nos chamava para mostrar o que havia conseguido fazer ou para compartilhar alguma ideia. Abrindo este espaço para que ele se expressasse de forma diferente, criou-se a possibilidade para que houvesse um novo olhar dele a respeito de si mesmo, no qual foi capaz de perceber sua potencialidade, desestigmatizando um olhar já instituído dentro da sala em relação a ele.

Foram realizados 14 encontros com os alunos, 4 encontros com a equipe gestora, 4 encontros com os professoras e 1 com os pais.

Quadro 1

Atividades desenvolvidas na EMEF Geração do Morro em 2013

\begin{tabular}{|c|c|c|}
\hline MESES & $\begin{array}{l}\text { ATIVIDADES } \\
\text { DESENVOLVIDAS }\end{array}$ & DESDOBRAMENTOS \\
\hline Março & $\begin{array}{l}\text { Observação da instituição, das } \\
\text { relações entre os personagens da } \\
\text { comunidade escolar e do entorno } \\
\text { da escola. Conversas com os } \\
\text { professores, gestores } \\
\text { funcionários da } \\
\text { elaboração da proposta de } \\
\text { intervenção. }\end{array}$ & $\begin{array}{l}\text { Percepção de que os alunos } \\
\text { estavam excluídos do processo de } \\
\text { compreensão da demanda, o que } \\
\text { levou à elaboração da proposta de } \\
\text { intervenção. }\end{array}$ \\
\hline Abril & $\begin{array}{l}\text { Continuação das observações e } \\
\text { diálogos com a comunidade } \\
\text { escolar. } \\
\text { Participação em evento de } \\
\text { educadores da Zona Norte. }\end{array}$ & $\begin{array}{l}\text { Elaboração da proposta } \mathrm{de} \\
\text { intervenção. }\end{array}$ \\
\hline Maio & PERÍODO DE GREVE & $\begin{array}{l}\text { Discussão das questões relativas à } \\
\text { greve em supervisões e } \\
\text { assembleias, aproximação dos } \\
\text { estagiários da situação do professor } \\
\text { da rede pública; diálogo sobre as } \\
\text { reinvindicações daquele momento. }\end{array}$ \\
\hline Junho & $\begin{array}{l}\text { Reelaboração da proposta e } \\
\text { comunicação para a comunidade } \\
\text { escolar a respeito do trabalho a } \\
\text { ser realizado. Esclarecimento dos } \\
\text { objetivos a toda a comunidade } \\
\text { escolar, de modo a convidá-la } \\
\text { para dialogar com o projeto. } \\
\text { Atividade com os diversos } \\
\text { grupos de } 8 \text { alunos de } 3^{\circ} \text { e } 4^{\circ} \text { ano } \\
\text { com objetivo de realizar registro } \\
\text { coletivo (desenho e escrita) } \\
\text { pensando: "o que falta na sua }\end{array}$ & $\begin{array}{l}\text { Estabelecimento de uma relação de } \\
\text { diálogo e confiança com } \\
\text { professores, alunos e gestores. } \\
\text { Percepção das diversas demandas } \\
\text { apresentadas pelos alunos a } \\
\text { respeito do espaço da escola, das } \\
\text { relações que nela se estabelecem e } \\
\text { do significado que ela ocupa em } \\
\text { suas vidas, do ponto de vista } \\
\text { pedagógico, social e individual. } \\
\text { Abertura de um espaço de escuta } \\
\text { dos alunos. }\end{array}$ \\
\hline
\end{tabular}


escola?".

Socialização dos desenhos de cada grupo no mural da escola.
Desconstrução de alguns perfis estigmatizados de certos alunos a partir da construção de grupos heterogêneos para participação no trabalho.

Pedido de encaminhamento de atendimento individual por parte de um aluno a partir da relação de confiança e da possibilidade de escuta que se estabeleceu.

\begin{tabular}{|c|c|c|}
\hline $\mathrm{o}$ & $\begin{array}{l}\text { Continuação da atividade de } \\
\text { reflexão com os alunos sobre a } \\
\text { pergunta "O que falta na sua } \\
\text { escola?". } \\
\text { Categorização das demandas dos } \\
\text { alunos em três categorias: "Dá } \\
\text { para fazer", "Não dá para fazer } \\
\text { agora" e "Já tem na escola e } \\
\text { pode ser mais bem aproveitado". } \\
\text { Atividade conjunta com todas as } \\
\text { salas correspondentes dos } \\
\text { pequenos grupos de alunos. } \\
\text { Discussão sobre } \\
\text { possibilidades diante das } \\
\text { demandas apresentadas pelos } \\
\text { alunos com os pequenos grupos. } \\
\text { Discussão com a coordenação } \\
\text { sobre dois casos individuais de } \\
\text { alunos e possibilidades de } \\
\text { encaminhamento da situação. }\end{array}$ & $\begin{array}{l}\text { Percepção do aspecto simbólico das } \\
\text { demandas apresentadas } \\
\text { concretamente pelos alunos. } \\
\text { Socialização do projeto com } \\
\text { professores e alunos para } \\
\text { acompanhamento do projeto na } \\
\text { escola. } \\
\text { Percepção da demanda por mais } \\
\text { espaços lúdicos e do auto- } \\
\text { reconhecimento no ambiente } \\
\text { escolar. } \\
\text { Percepção por parte dos alunos do } \\
\text { seu protagonismo em relação às } \\
\text { mudanças em sua escola, em que } \\
\text { pudessem ser autonomamente } \\
\text { integrantes dos processos de } \\
\text { transformação. } \\
\text { Possibilidade de um outro olhar } \\
\text { para os alunos, agora fora da } \\
\text { situação de sala de aula. }\end{array}$ \\
\hline
\end{tabular}

Setembro Conversa particular a partir da demanda de uma professora.

Apresentação da tabela de categorização elaborada pelos alunos para professores e gestores.

Abertura de espaço para escuta dos professores sobre suas dificuldades em sala de aula e percepção da possibilidade de oferecer aos profissionais um espaço exclusivo de acolhimento e reflexão sobre sua Participação na reunião de pais e prática. sugestão de dinâmica.

Proposta de colocar em prática alguma mudança que pudesse se concretizar ainda no ano em que o projeto estaria vigente.

Elaboração de cartazes a respeito da melhor utilização do banheiro da escola e da higiene neste ambiente.
Percepção geral das demandas e soluções encontradas pelos alunos.

Possibilidade de repensar o formato de reunião de pais para que houvesse espaço para críticas, elogios e sugestões de resolução.

Alunos protagonistas do processo de mudança, realizando autonomamente alguma 
Elaboração de uma carta para a coordenação com um pedido dos alunos para uma conversa com todos os alunos sobre a higiene no banheiro. transformação no ambiente escolar. Reflexão, a partir da reunião de pais, da apropriação dos professores do projeto políticopedagógico da escola.

\begin{tabular}{|c|c|c|}
\hline Outubro & $\begin{array}{l}\text { Oficina de Pipas oferecida na } \\
\text { semana da criança. } \\
\text { Reunião com os professores das } \\
\text { séries participantes do projeto. } \\
\text { Elaboração das regras do jogo de } \\
\text { pebolim. } \\
\text { Confecção de bandeirinhas para } \\
\text { enfeitar o ambiente escolar. }\end{array}$ & $\begin{array}{l}\text { Possibilidade de experimentação } \\
\text { dos alunos de uma relação } \\
\text { horizontal diante do aprendizado e } \\
\text { de outras formas de expressão. } \\
\text { Reflexão com professores e } \\
\text { gestores sobre o atual momento da } \\
\text { educação e os desdobramentos } \\
\text { deste contexto na prática diária dos } \\
\text { profissionais envolvidos. } \\
\text { Elaboração conjunta com } \\
\text { professores e gestores de sugestões } \\
\text { de práticas que poderiam contribuir } \\
\text { para qualidade do trabalho do } \\
\text { professor e dos alunos em sala de } \\
\text { aula. } \\
\text { Oportunidade aos alunos de auto- } \\
\text { regulação diante dos conflitos a } \\
\text { partir da elaboração conjunta de } \\
\text { regras e discussão sobre o sentido } \\
\text { de elaborar e cumprir regras. } \\
\text { Oportunidade aos alunos de se } \\
\text { expressar no ambiente físico da } \\
\text { escola, podendo ampliar sua } \\
\text { identificação com instituição. } \\
\text { Depoimento de um aluno } \\
\text { participante da Oficina de Pipas } \\
\text { sobre a repercussão de sua } \\
\text { participação na oficina que } \\
\text { possibilitou a construção conjunta } \\
\text { com seu pai de uma pipa, dando } \\
\text { sentido no "aqui agora" do } \\
\text { aprendizado escolar. } \\
\text { Descristalização de papéis de } \\
\text { alunos diante do aprendizado a } \\
\text { partir da vivência de outros } \\
\text { recursos expressivos, como, por } \\
\text { exemplo, na confecção de } \\
\text { bandeirinhas. }\end{array}$ \\
\hline
\end{tabular}


por dispositivos culturais na diante disso.

região. Produção de um cartaz sobre

Confecção de uma história em expectativa de futuro que foi quadrinhos por parte das afixado no mural da escola estagiárias como forma de juntamente com outros em branco encerramento com os alunos. para socializar para a comunidade Encerramento do projeto com escolar a possibilidade de reflexão alunos. sobre o assunto.

Reflexão com os gestores sobre o Reconhecimento pela comunidade processo vivenciado e escolar de outras possibilidades de encerramento do projeto. instituições do território que Conversa pontual com pudessem oferecer espaços professores sobre o encerramento diferenciados para aprendizado e do projeto. acesso à cultura.

Através da história em quadrinhos oferecimento aos alunos de uma possibilidade de relembrar o projeto, bem como seu protagonismo diante das mudanças. Percepção das demandas para futuras intervenções e sugestões de melhoria nos próximos projetos e parcerias.

Demanda específica sobre um espaço para professores, para discussão tanto de estratégias pedagógicas como de acolhimento de angústias e reflexões.

Para concluir o estágio, foi oferecida uma história em quadrinhos que retratava todo o processo desenvolvido pelos alunos envolvidos na proposta, ao longo do ano. Eles podiam pintar da maneira que quisessem o desenho e levá-lo para casa. Desta forma, além de ter algo concreto para guardar desta vivência, puderam ter a noção global do trabalho e do que foi necessário para dar cada passo, sendo possível dar continuidade independentemente da presença das estagiárias. A possibilidade de pintar e completar a história da maneira que desejassem traria a marca pessoal de cada um, dando o colorido ao projeto.

\section{O QUE SE MOSTROU: CAMINHOS PERCORRIDOS, SOLUÇÕES POSSÍVEIS/IMPOSSÍVEIS}

A partir dos relatos das atividades grupais realizadas com os alunos, e na consideração da demanda, foi feito um levantamento de insatisfações dos educandos frente ao cotidiano 
escolar, buscando-se quais necessidades, segundo sua percepção, não estavam sendo atendidas pela escola. Em seguida realizaram-se encontros com estudantes e equipe pedagógica, com o propósito de encontrar soluções possíveis, dentro dos limites da atuação da escola. Construiu-se, em conjunto com a escola, um espaço de escuta que desse voz às impressões e opiniões, na consideração de todos os participantes como sujeitos capazes de se expressar com propriedade.

Com os relatos de todas as reuniões em mãos, construiu-se coletivamente, com participação de estudantes e educadores. O Quadro 2 contêm as falas, reclamações, opiniões dos alunos, organizadas segundo as seguintes categorias: demandas viáveis, que são aquelas que poderiam ser resolvidas com o esforço do coletivo ("Dá para fazer”); demandas relacionadas às condições que já existem na escola e que não são bem aproveitadas ("Já tem na escola e precisa ser melhor aproveitado"); demandas inviáveis ("Não dá para fazer"); soluções.

No tópico referente às demandas viáveis, apareceram falas que foram levadas adiante no projeto, tais como: "Ter mais aulas livres de informática"; "Fazer uma festa de despedida quando for para o $5^{\circ}$ ano"; "Ter uma rádio na escola que toque música para dançar”; "Aula de natação"; "Ter um momento para falar sobre o futuro com as estagiárias da PUC"; "Respeitar os mais velhos"; "Menos bagunça na sala de aula"; "Ter mais bandeirinhas enfeitando a escola"; "Poder deixar a bicicleta na escola".

Em relação às demandas inviáveis (por eles apresentadas como inviáveis ou temporariamente inviáveis), foram trazidas falas como: "Ter uma doceria na escola"; "Ter um laboratório com ratinhos na escola"; "Ter alguém que copie a lição para nós”; "Ter um quarto para dormir na escola"; "Piscina na escola"; "Ser recreio em todas as aulas".

Algumas reflexões, entretanto, dizem respeito à possibilidade de se aproveitar mais o que já existe na escola, ou seja, caracterizam-se como demandas para se potencializarem os equipamentos e relações na escola. Essas se traduzem em falas como: "Ter brincadeiras de roda depois das atividades"; "Ter um momento para discutir quem gosta de quem"; "Variar mais os espaços da escola"; "Ter cama elástica, piscina de bolinha e pula-pula"; "Poder dar mais risada na sala de aula"; "Telão na escola para assistir à Copa".

As reflexões que aconteceram no sentido de solucionar as questões apresentadas ou de problematizá-las, quando eles entendiam que não havia solução possível até o momento, também foram trabalhadas coletivamente e sistematizadas num quadro que ficou disponível 
para a escola, de forma que todos pudessem pensar sobre os desafios apontados em outros momentos além daquele do encontro com as estagiárias.

Quadro 2

Soluções propostas pelas crianças - EMEF Geração do Morro

\begin{tabular}{ll}
\hline Falas das crianças & $\begin{array}{l}\text { Categoria } \\
\text { pelos alunos }\end{array}$ \\
\hline $\begin{array}{l}\text { "Ter mais aula livre } \\
\text { de informática" }\end{array}$ & Dá para fazer"
\end{tabular}

"Ser recreio em "Não dá" todas as aulas" escolhida Soluções/Discussões

Sugeriram deixar a professora falar para que pudesse sobrar um tempo para momentos livres. Ficar em silêncio durante a aula ajudaria todos a se focarem no que deveria ser feito para depois poder ter o tempo livre. Sugeriram também dois dias de aula e dois de aula livre, porém conversamos sobre isso e eles chegaram à conclusão de que não era possível para a professora passar todo o conteúdo que eles precisavam aprender em apenas duas aulas. Concordaram que o conteúdo era importante.

A maioria dos alunos no início respondeu que sim, mas durante a conversa concluíram que eles vêm para a escola por um motivo: aprender, estudar e também se divertir. Buscaram outras sugestões como aproveitar tanto o recreio como as aulas. Apontaram que também se aprendem coisas no momento do intervalo.

"Fazer uma festa de "Dá para fazer" despedida quando for para $05^{\circ}$ ano"
Neste dia duas alunas estavam comemorando, antes do início da atividade, que elas haviam sido autorizadas a organizar uma festa. A partir disso já puderam pensar em como se organizar e saber que isso era possível de se fazer. Surgiu, no entanto, um conflito quanto a quem convidar para essa festa, já que outra sala estava fazendo uma festa para a 
qual eles não tinham sido convidados. Estavam bravos com isso, decidindo então por não convidar a outra sala para festa que organizariam. Conversamos um tempo sobre isso, discutindo se seria mais interessante continuar com essa "exclusão" ou se uma festa com todo mundo seria mais legal, por ter mais amigos, mais comida, mais diversão e mais possibilidade de conhecer pessoas novas.

"Ter uma rádio na "Dá para fazer"
escola que pudesse
tocar música para
dançar"

Os alunos primeiro sugeriram que cada um trouxesse um rádio de casa para tocar música na aula. Com a conversa chegamos à conclusão de que ter aula e ouvir música ao mesmo tempo não seria possível, então os alunos procuraram outros momentos. Sugeriram que isso acontecesse no intervalo, pois assim eles poderiam escolher as músicas. Deveria ser reservado um espaço para isso, uma vez que $o$ barulho do recreio atrapalharia se fosse em todo o pátio. Lembraram que já existia um rádio na escola e eles poderiam pedir emprestado.

\begin{tabular}{llrl}
\hline "Telão & na escola & "Já tem na escola e \\
para assistir & a precisa ser melhor \\
Copa" & & & aproveitado"
\end{tabular}

O primeiro ponto a ser discutido foi a diferença entre os gostos dos meninos e das meninas, pois eles iriam querer ver os jogos e elas não. Discutiram a hipótese de ter dois telões, mas isso seria mais difícil, por ser caro. Pensaram que cada um poderia dar um pouco do dinheiro ou que poderiam fazer uma festa para arrecadar. Lembraram então que já tinha uma televisão grande na escola e, para não ter confusão, na hora de escolher o que assistir, cada um levaria um filme e haveria uma votação. Disseram que isso já acontecera e tinha sido bem legal. 
"Poder dar mais "Ja risada na sala de precisa ser melhor aula"
A sugestão da maioria foi que eles se concentrassem para fazer a lição e sobraria um tempo livre para que pudessem brincar e dar risada. Relembramos, no entanto, o quanto estava difícil que eles se concentrassem mesmo em poucos alunos e falando sobre um assunto que seria de interesse deles. Apontamos que isso poderia atrapalhar esse combinado. Conversamos sobre cada um tentar se controlar e talvez ajudar o amigo para que pudesse se controlar também. Foi considerado deixar em lugar visível para todos qual era a brincadeira que aconteceria se eles se concentrassem, para lembrá-los do combinado. Também foi sugerido que houvesse algo, na própria aula, uma atividade diferente, com momentos em que seria possível dar risada também.

"Ter cama elástica, "Já tem na escola e Num primeiro momento
piscina de bolinha e precisa ser melhor disseram que era possível: era pula-pula" aproveitado"

somente preciso encontrar um espaço. Conversamos sobre o que precisaria ter para conseguir esses brinquedos e eles falaram que necessitaria de dinheiro. Sugeriram uma festa para conseguir arrecadar dinheiro, no entanto também era preciso alguém que cuidasse dos brinquedos. Perceberam que naquele momento não era possível, mas que, na semana da criança e em festas, esses brinquedos estariam presentes e então poderiam ser aproveitados.

\begin{tabular}{lll}
\hline "Piscina na escola" "Não dá para fazer & $\begin{array}{l}\text { A primeira sugestão foi retirar os } \\
\text { brinquedos do parquinho e } \\
\text { agora" }\end{array}$ \\
& colocar a piscina lá. Mas, com o \\
& espaço supostamente resolvido, \\
& perceberam que era necessário \\
& muito dinheiro para que se
\end{tabular}




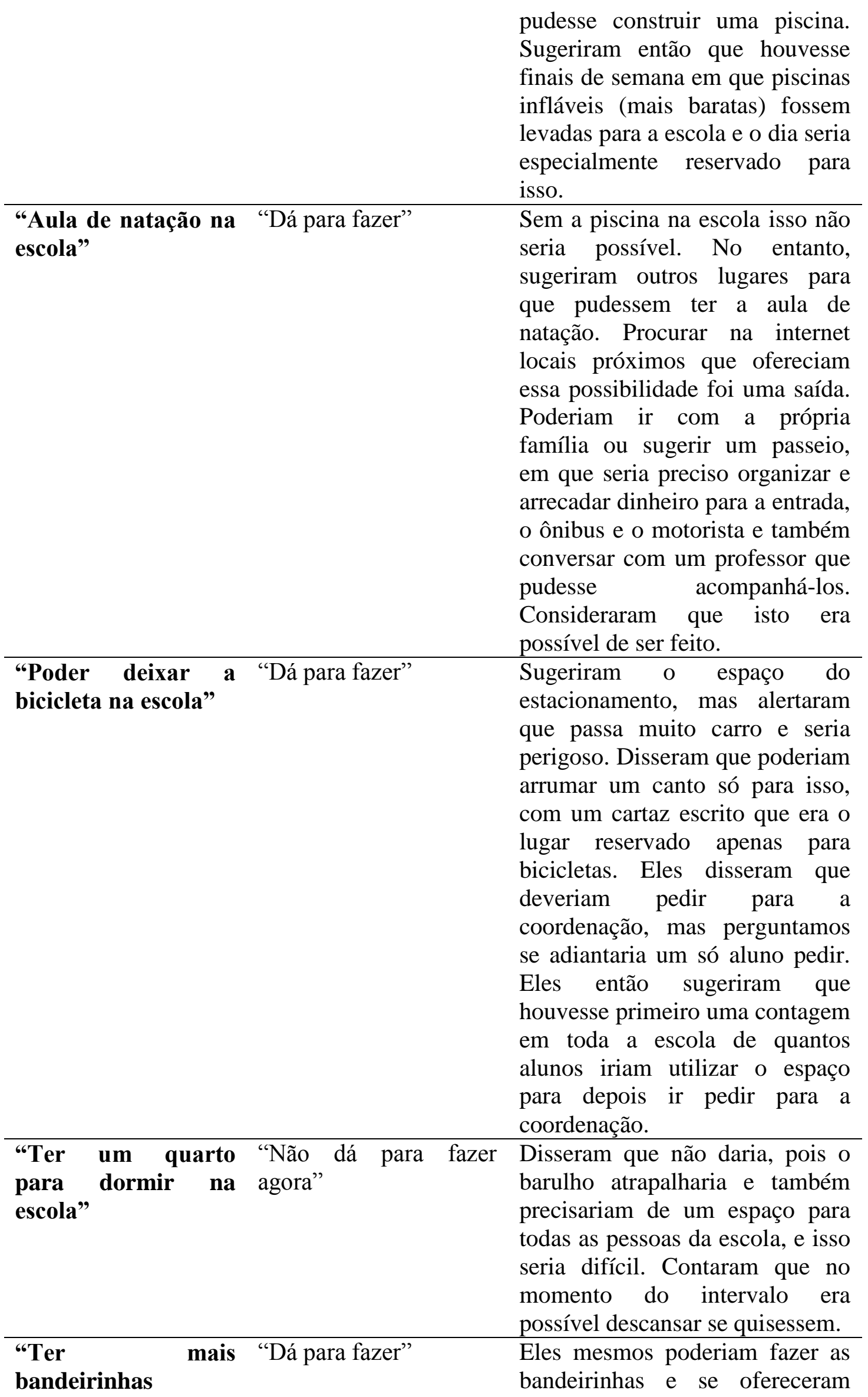


enfeitando a escola" para trazer de casa o material. Conversamos em que momento e com qual material isso poderia ser feito. Chegaram à conclusão de que a aula de artes seria uma boa oportunidade e que haveria pelo menos parte dos materiais necessários.

\begin{tabular}{ll}
\hline "Variar mais os "Já tem na escola e \\
espaços da escola" \\
$\begin{array}{l}\text { precisa ser melhor } \\
\text { aproveitado" }\end{array}$
\end{tabular}

Sugeriram usar outros espaços que não a sala de aula antes e depois do recreio e, quando a professora faltasse, perguntar qual espaço poderiam utilizar. Consideraram também mudar a própria sala com alguns enfeites de acordo com a atividade (por exemplo, fazer uma cabana). Isto poderia ser uma proposta relacionada à matéria que estivessem estudando no momento.

\begin{tabular}{l}
\hline "Ter um momento "Já tem na escola e \\
para discutir quem precisa ser melhor \\
gosta de quem"
\end{tabular}

Eles disseram que podiam conversar sobre isso durante a aula, com a professora, e também no recreio. $\mathrm{Na}$ aula nem sempre era possível, pois eles tinham outras atividades. Sugeriram então o dia do parque para isso. Outra ideia foi a de criar um correio elegante para que pudessem mandar cartas $\mathrm{e}$ bilhetes para outros alunos, outra forma de mostrar quem gosta de quem.

"Menos bagunça na "Dá para fazer" Discutimos que existem sala de aula" momentos em que dá para fazer bagunça e outros em que não. Disseram que deveriam se esforçar para não fazer bagunça, mas foi preciso retomar novamente o quão difícil era para eles, mesmo nessa atividade. Eles perceberam isto. Sugeriram que parar de beijar dentro da sala, parar de comer na sala e não gritar para chamar o colega eram boas alternativas para diminuir a 
bagunça. Também disseram que poderiam falar com os amigos mais baixo e ajudá-los a não bagunçar.

\begin{tabular}{ll}
\hline "Respeitar os mais "Dá para fazer" & Falaram que tinha muito \\
velhos" & xingamento na escola. Pensamos \\
& junto com eles que queremos \\
& xingar quando estamos com \\
& muita raiva e que seria legal se \\
& acalmar antes de falar com o \\
& amigo, professor ou inspetor que \\
& os está deixando bravos. Deram \\
& várias sugestões para isso, como \\
& contar até dez ou até fechar os \\
& olhos e meditar. Eles falaram que \\
& muita gente xinga e então \\
& poderiam construir um cartaz \\
& com toda a sala, em que \\
& houvesse um combinado quanto \\
& a esse problema. Ficaram \\
& empolgados para fazer estes \\
& combinados. \\
\hline
\end{tabular}

"Ter alguém que "Não dá para fazer por Comentaram que isto não era copiasse a lição para enquanto" nós" possível, pois, se fosse assim, não iriam aprender nada. Falaram sobre a importância de aprender para o próprio futuro e que não era possível ficar a vida toda copiando de alguém. Também disseram que em algumas atividades poderiam ter ajuda, pois esta seria outra forma de aprender.

"Ter um momento "Dá para fazer"
para falar sobre o
futuro com as
estagiárias da PUC"

Compararam as atividades com o que faziam com o Projeto Brincante, dizendo que era diferente e novo para eles. Comentaram que podiam falar sobre o futuro com a professora $\mathrm{e}$ com outras pessoas da escola, mas que havia poucos momentos para isto e normalmente a discussão girava em torno de um futuro próximo. Gostariam que o estágio da PUC pegasse uma sala inteira para desenhar e falar sobre o futuro com eles. Perguntamos como isso poderia acontecer e falaram que tanto 
eles quanto nós poderíamos pedir para os próximos estagiários para ter esta atividade. Apontamos que um só aluno falar com os próximos estagiários talvez não fosse tão efetivo como se um grupo maior falasse e pensaram em pedir junto com vários outros alunos para ter este momento. Consideraram algo que pode ser feito.

"Ter brincadeiras de "Já tem na escola e
roda depois das precisa ser melhor
atividades"

Discutiram que se obedecessem à professora e fizessem todas as lições poderiam ter este tempo de brincadeira. Falaram que alguns professores observavam o comportamento da sala e não prometiam nada, mas davam brincadeira quando notavam que todos estavam tendo uma atitude adequada. Algumas vezes quem não tinha feito a lição não participava destes momentos. Perguntamos se não seria mais legal se todos pudessem ter este tempo para brincar e como isto poderia acontecer. Contaram que eles tinham feito junto com a professora um cartaz com as regras da sala e com as consequências (que eles mesmos decidiram), mas que não conseguiam cumprir. Arrependeram-se, mas a princípio tinham achado que isto ia dar certo. Comentaram que já haviam feito uma carta para a professora, pedindo que ela gritasse menos, e uma conversa com ela, pensando em como melhorar o comportamento da sala. Apontamos que era difícil não gritar algumas vezes, pois, por exemplo, no próprio grupo estava difícil para falarmos em alguns momentos e eles só estavam em 9. Sugerimos também que eles poderiam tentar 
se ajudar, conversando com os colegas que não estavam cooperando e apontando que isto fazia com que todo o grupo perdesse momentos de brincadeira. Reclamaram que era difícil conversar com a direção e com a coordenação, pois havia muita gritaria. Ao mesmo tempo, consideraram que a professora tinha razão quando chamava a atenção e colocava para fora da sala. Pensaram na possibilidade de sentar em duplas para um ajudar o outro a se concentrar. Reclamaram que se uma menina senta com um menino todo mundo fala que estão namorando. Apontamos que, se nem eles mesmos conseguiam se respeitar entre si, ficava difícil respeitar a professora. Concordaram que precisavam se respeitar mais e que havia momentos para brincadeira e outros para falar sério. Disseram que seria possível mostrar para o colega que não gostaram de uma atitude dele de modo respeitoso, sem gritar ou xingar. Consideraram que seria possível aproveitar mais os momentos de brincadeira se conseguissem melhorar sua organização e que isto já acontecia na escola.

"Ter um laboratório "Não dá por enquanto"
com ratinhos na
escola"

Ajudamos os alunos a pensar o que seria necessário para ter um laboratório na escola e o investimento envolvido nisto. Pensaram em formas de arrecadar dinheiro (pedindo para os pais, fazendo festas, shows e feira de artesanato para arrecadação). Comentaram que já fizeram um teatro das crianças para conseguir dinheiro e que poderiam fazer novamente. Afirmamos que isto era algo que dependia deles, e não dos pais, e 
que era uma boa ideia. Também pensaram em descobrir se havia algum lugar que doasse coisas seminovas para o laboratório da escola. Comentamos que um laboratório tem coisas perigosas e que provavelmente o equipamento precisa ser novo. Pensaram então em algum lugar que doasse coisas que eles pudessem vender para arrecadar dinheiro. Consideraram a possibilidade de dar alguma aula paga e apontamos que desta forma talvez não fosse interessante, pois nem todos poderiam participar. Consideraram que poderiam tentar arrecadar dinheiro para o laboratório, mas que isto não poderia ser resolvido naquele momento.

"Ter aula de "Já tem na escola e
culinária na escola"
$\begin{aligned} & \text { precisa ser melhor } \\ & \text { aproveitado" }\end{aligned}$

Comentaram que cada um (quem pudesse) poderia trazer algo de casa para cozinharem. Cada vez uma sala poderia fazer isto. Pensaram em vender a comida ou a aula de culinária para arrecadar dinheiro para um laboratório da escola. Contaram que já haviam cozinhado bolo de milho com a professora e que dava para fazer a receita numa sala, para não atrapalhar as cozinheiras, e depois assar as coisas na cozinha.

"Ter uma doceria na "Não dá por enquanto" escola"
Apontaram que achavam que não era possível, pois algumas crianças não teriam dinheiro para comprar doce e seria necessário arrecadar dinheiro não só para um laboratório, como para a própria doceria. Comentaram que faltaria espaço e que já tem uma doceria na frente da escola. Também disseram que podiam trazer doce de casa e dividir entre as crianças, ou que podiam fazer um piquenique, como já 
aconteceu antes. Falaram que alguns alunos não gostavam da comida da escola, mas que a maioria gostava. Apontamos que a escola é um lugar para aprender e que comer coisas diferentes é um jeito de aprender. Falamos que a comida era escolhida por uma nutricionista que sabia de coisas que faziam bem para a saúde e que alguns doces não fazem bem para o corpo e para os dentes, de maneira que muitos pais não concordariam com uma doceria dentro da escola. Alguns contaram coisas que experimentaram na escola e que passaram a gostar de comer. Comentaram que as cozinheiras às vezes colocam comida demais, mesmo quando eles pedem para por menos e que não gostam quando elas usam a colher da comida salgada para servir a sobremesa. Disseram que já reclamaram sobre isso antes. Embora estivesse desvinculado da discussão inicial, comentaram que poderiam ajudar a limpar a escola. Alguns objetaram, dizendo que a escola era para estudar e que criança não trabalha. Concordamos que não era possível limpar a escola como trabalho, mas que eles podiam contribuir para deixar a escola limpa e cuidar do material. Para encerrar a conversa, concordaram que não seria possível ter uma doceria na escola e que havia outros espaços onde poderiam comer doces.

Muitos temas atravessaram as sugestões e soluções trazidas por eles como: administrar um telão quando meninos gostam de futebol e meninas não? (Gênero); é possível ouvir 
música durante a aula? (Respeito ao professor e ao espaço de estudo); É possível ter dois telões? (Custos); Como fazer sobrar tempo livre (Responsabilidade pela organização da agenda). As discussões ensejadas por tais temas foram ricas e contribuíram para uma educação para a cidadania.

Eles efetivamente pensaram em soluções específicas para cada uma das demandas e refletiram com cuidado, junto com as estagiárias, sobre aquelas que pareciam inviáveis, como, por exemplo, construir uma piscina dentro da escola ou, ainda, fazer natação na própria escola. Sem a piscina na escola o esporte não seria possível. No entanto, sugeriram outros lugares em que pudessem ter a aula de natação. Procurar na internet locais próximos que ofereciam essa possibilidade foi uma saída. Poderiam ir com a própria família ou sugerir um passeio, em que seria preciso organizar e arrecadar dinheiro para a entrada, o ônibus e o motorista e também conversar com um professor que pudesse acompanhá-los. Consideraram que isto era possível de ser feito e, de fato, foi feito um levantamento de locais, como fazer matrícula e como chegar, a partir do reconhecimento territorial feito inicialmente pelas estagiárias, juntamente com o conhecimento deles sobre o território, mais profundo e genuíno por lá habitarem.

Os alunos, aos poucos se tornaram ativos e protagonistas. Como exemplo disso, podemos citar a forma como eles foram capazes de colocar em prática, de forma independente da coordenação e dos inspetores, no momento do intervalo, as regras do pebolim, elaboradas conjuntamente com os estagiários na situação do grupo.

Inspirada pela proposta do estágio, que valorizava o potencial de participação dos alunos, uma professora relatou ter utilizado as ferramentas específicas de sua disciplina para que as crianças pudessem escrever-lhe e-mails falando de suas impressões sobre a sua aula. Sugeriu a outros professores que fizessem o mesmo. Dessa forma, criou um espaço em que cada aluno pode se perceber como atuante e transformador a seu modo. O conhecimento sobre a ferramenta tornou-se significativo quando pôde tratar de algo útil para sua vivência escolar, dando mais sentido ao aprender.

Outro exemplo sobre o reconhecimento dos alunos da importância da participação nas decisões que são de sua alçada foi o cartaz que falava sobre projeto de futuro afixado na escola, que convidava outros, fora dos pequenos grupos contemplados semanalmente, para participação em sua elaboração. De uma semana para a outra, o cartaz foi preenchido e a 
maioria das contribuições continha assinaturas, demonstrando o valor de reconhecer-se como personagem importante para o coletivo.

O trabalho em grupo possibilitou a reflexão sobre modos de conduta que poderiam ou não ajudá-los. Ao realizar uma tarefa de formulação conjunta de regras de convivência em sala de aula foi possível fazer alguns apontamentos sobre como algumas formas de agir dos alunos (fazer bagunça) desfavoreciam seus próprios interesses ("ter mais tempo para conversar e dar risada") e o cumprimento das regras por eles elaboradas.

A análise da escola, no decorrer e final do projeto, apontou para vários itens importantes: sugeriram espaços (não apenas geográficos) para que o trabalho fosse feito, fizeram avaliações críticas e positivas. Algumas atividades foram incorporadas em aulas; alguns alunos puderam se manifestar de outra forma, desenvolvendo outras potencialidades e se mostrando cooperativos e criativos, podendo sair, assim, de um estereótipo já reforçado pelo grupo (o bagunceiro, o que não sabe nada); a professora que ensinava tecnologia aproveitou o tema do projeto em sua aula, incentivando os alunos a escreverem por e-mail o que tinham trabalhado, ou seja, sua opinião sobre a escola; o fato de cartazes terem sido afixados no corredor da escola com as reflexões desse grupo impulsionou outras crianças de outras turmas a participarem, já que havia, nesses cartazes, espaço para outras pessoas da escola de manifestarem, não apenas os diretamente ligados ao estágio. Por fim, o pedido de outros professores e gestores para que o estágio fosse direcionado a outras classes e idades reforçou o sentido que o trabalho fazia coletivamente. A continuidade foi garantida no estágio posterior e, de forma mais geral, na parceria que a escola realiza com a universidade por meio dos estágios de $4^{\circ}$ e $5^{\circ}$ anos da graduação de Psicologia.

\section{ALGUMAS CONSIDERAÇÕES À GUISA DE CONCLUSÃO}

Se retomarmos a epígrafe de Lispector (1992, p. 12), veremos que a última frase " na minha pressa eu crescia sem saber para onde" ilustra, de algum modo, uma interessante concepção de "desenvolvimento" não linear, indicando, entretanto, crescimento sempre. Podemos entender que a presença das estagiárias pode ter sido fundamental para indicar alguma direção e o sentido de suas demandas, assim como as condições necessárias para seu atendimento. Essa é umas das finalidades de intervenções psicoeducativas. 
Quando se promove um espaço de escuta, as diferentes vozes institucionais são trazidas à tona, pessoas se movimentam e ocupam outros lugares e um desgelamento pode acontecer. Ao referir-se ao significado da palavra "casa", Arendt lembra que ela se refere a algo que vai além de uma construção concreta, mas se refere a um lugar que abriga, um lugar que se habita. "A palavra 'casa' é como um pensamento congelado que o ato de pensar tem que descongelar sempre que se pretende encontrar seu significado original” (ARENDT, 2002, p. 129). Os encontros constituíram-se como oportunidades de se pensar sobre necessidades, demandas e valores, como respeito aos colegas e professores e consideração de diferenças entre os gêneros.

Um aspecto importante do presente trabalho é que ele, embora tenha tido como foco as crianças da escola, envolveu participantes de todo espaço escolar (professores, alunos, coordenadores, faxineiros, diretor, cozinheiros, equipe de apoio), revelando que no espaço escolar todos os adultos são (ou devem ser) educadores. Essa condição possibilitou que os participantes contribuíssem de forma inédita e criativa com o coletivo. Isto pôde ser observado ao longo do trabalho em muitos momentos, pois a proposta previa a construção de soluções conjuntas com os alunos nas quais a participação criativa, tanto dos alunos como de outros atores, era imprescindível.

Assim, ao pensar sobre seus desejos dentro de um espaço socialmente compartilhado, foi favorecida a compreensão (neste caso a partir da fala dos alunos) e a tomada de consciência de que há espaço para sua existência como participante ativo dentro do coletivo, tanto no espaço da escola, quanto na sociedade, como cidadãos com recursos para intervir em seu mundo. Freire, num sentido mais radical, refere-se à conscientização como "tomar posse da realidade" (FREIRE, 1980, p. 29) associando-a ao processo de libertação. A EMEF, que apoiou a intervenção em todos os momentos, assumiu a proposta freireana de uma educação libertadora, em que a ação educativa “... deve estar infundida da profunda crença nos homens. Crença no seu poder criador" (FREIRE, 1987, p. 62).

Podem-se perceber reverberações do trabalho em outros espaços e horários. Uma situação de espraiamento das experiências vividas durante o projeto foi o caso de um garoto que, após a Oficina de Pipas, oferecida pelas estagiárias na semana da criança, relatou que havia feito outra pipa na companhia de seu pai e ambos empinaram juntos. Assim, vemos transbordamento da questão trabalhada dentro do espaço escolar para a dimensão familiar. Isto mostra como o aprendizado pôde ter uma repercussão afetiva na vida dessa criança sem 
que a escola precisasse interferir diretamente no sentido de formar um vínculo com as famílias. Nesse caso, o conhecimento de construir uma pipa foi uma ponte de diálogo entre pai e filho, fazendo com que a aprendizagem tivesse um sentido para sua vida atual.

Outra situação, que evidenciou o trabalho com grupos como oferecendo oportunidade de ampliação das experiências para fora de seus muros, foi a busca espontânea de orientação para atendimento psicológico de um aluno que veio à procura das estagiárias ao perceber a abertura desse espaço. Essas situações mostram que a escola pode tornar-se um local no qual o indivíduo pode encontrar suporte e recursos para construir pontes com o mundo mais amplo.

É importante ressaltar que o trabalho do psicólogo no espaço escolar inclui o acolhimento do educador, bem como o de oferecimento de um espaço em que possam compartilhar experiências, sensações, sentimentos e angústias, além de ajudá-los a buscar ferramentas que os fortaleçam em seu papel. Essa demanda foi apresentada pelas educadoras na etapa de devolutivas de nosso trabalho, na qual puderam dar uma devolutiva sobre o que pensaram do projeto, quais as sugestões e críticas, bem como possibilidades de continuidade. Ficou clara a importância de haver um espaço em que os educadores pudessem ser acolhidos e refletir acerca de seu papel, suas angústias frente a ele e as possibilidades de enfrentamento.

Essa ação abriu espaço para a continuidade da parceria que garante presença de pessoas em formação (no caso, psicólogos em formação) no espaço da escola, e garantiu a continuidade de um projeto que foi coletivamente denominado "Projeto Escuta" e que se consolida em ambas as instituições (escola e universidade) abrindo um importante espaço de discussão sobre a inserção do psicólogo na escola e, em última instância, sobre a diminuição do abismo que sabemos existir entre a universidade e a sociedade de maneira mais ampla.

\title{
MORRO'S GENERATION: A REPORT OF A PSYCHOEDUCATIONAL INTERVENTION IN A PUBLIC SCHOOL
}

\begin{abstract}
This article describes a psychological and educational intervention performed in a Municipal Elementary School located in Brasilândia, north of the city of São Paulo. The school, concerned about the transition of Primary Education (P.E.) first years students to P.E. final years, requested an intervention from the university. The project was planned to consider the
\end{abstract}


students' complains and aspirations and to build collectively, with the participation of the school staff, new ways to solve their day-by-day problems. The dialogic educational framework of Paulo Freire and the phenomenological perspective provided the actions' theoretical underpinnings. There were group activities and reflexive encounters, which showed that students became conscious of their place in the collective world of the school and that our work reverberated outside school walls, within families. It is important to highlight that the project welcomed the educators during activities in which they could share their experiences, feelings, sensations and concerns with specific situations, as well as seek new tools in order to strengthen themselves as educators. The school, after the project, requested for continuation of our partnership through a new project called "Projeto Escuta" (Listening Project). Our initiative opened an important space for discussion about the psychologist's insertion in the school community and contributed to find ways to reduce the abyss between university and society.

Keywords: Psychoeducational Practice; Psychologist Training; Phenomenology; Psychological Practices

\section{GENERACIÓN MORRO: INFORME DE UN PROYECTO DE INTERVENCIÓN PSICOEDUCATIVA EN UNA ESCUELA PÚBLICA}

\section{Resumen}

Este artículo tiene como objetivo describir una intervención psicoeducativa realizada en una Escuela Primaria Municipal ubicada en la región Brasilândia, al norte de la ciudad de São Paulo. A partir de la demanda de la escuela, preocupada por la transición de los estudiantes de los primeros años de la educación primaria para los últimos años, hemos puesto en marcha un proyecto de intervención destinada a dar voz al grupo de estudiantes, sistematizar sus quejas y aspiraciones y construir juntos las vías de solución de dificultades, incluyendo la participación de los profesores y el personal. La propuesta educativa dialógica de Paulo Freire y la perspectiva fenomenológica subyacía teóricamente las acciones y análisis desarrollados. Hubo actividades en grupo y encuentros reflexivos y el análisis mostró que, además de los estudiantes reconocieren que había lugar para vivir juntos como participantes activos en el 
colectivo escolar, hubo reverberaciones del trabajo en otros lugares y tiempos, como en la familia. Es importante destacar que el trabajo incluyó lo educador, con la creación de un espacio donde pudieran compartir experiencias, sensaciones, sentimientos, inquietudes y buscar herramientas que fortalecieron en su papel. La escuela, después de este proyecto, pidió la continuación de la asociación a través de un proyecto que se llama " Proyecto 'Escuta'". Esta iniciativa garantizó la presencia de psicólogos en formación en la escuela, abrió un importante espacio para el debate acerca de la inserción del psicólogo en la escuela y, en última instancia, acerca de la reducción del abismo que existe entre la universidad y la sociedad en general.

Palabras-clave: Prácticas Psicoeducativas; Formación De Los Psicólogos; Prácticas Fenomenología; Psicológicos

\section{REFERÊNCIAS}

ARENDT, Hannah. A vida do espírito. 4. ed. Rio de Janeiro: Relume-Dumará, 2002.

CRITELLI, Dulce Mara. Analítica do sentido. São Paulo: EDUC, 1996.

FREIRE, Paulo. Pedagogia da autonomia. Rio de Janeiro: Paz e Terra, 1998. . Pedagogia do oprimido. 17. ed. Rio de Janeiro: Paz e Terra, 1987. . Conscientização: teoria e prática da libertação. São Paulo: Editora Moraes, 1980.

GADAMER, Hans-Georg. Verdade e método. V. I. Petrópolis: Vozes, 2002.

HOUAISS, Antônio. Dicionário Houaiss da Língua Portuguesa. Rio de Janeiro: Objetiva, 2001.

LISPECTOR, Clarice. Os desastres de Sofia. In: A legião estrangeira. 10. ed. São Paulo: Siciliano, 1992. p. 7-25.

LÜCK, H.; FREITAS, K. S.; GIRLING, R.; KEITH, S. A Escola Participativa: o trabalho do gestor escolar. 3. ed. Petrópolis: Vozes, 2005.

MARTINS, J.; BICUDO, M. A. V. A Pesquisa qualitativa em Psicologia: fundamentos e recursos básicos. 5. ed. São Paulo: Centauro, 2005.

MINAYO, Maria Cecilia de Souza. O desafio do conhecimento: pesquisa qualitativa em Saúde. 12. ed. São Paulo: Hucitec, 2010. 
MORATO, Henriette Tognetti Penha. Aconselhamento psicológico centrado na pessoa: novos desafios. São Paulo: Casa do Psicólogo, 1999.

PUIG, Joaquim. Democracia e participação escolar: propostas de atividades. São Paulo: Moderna, 2000.

SZYMANSKI, Heloisa. Entrevista reflexiva: um olhar psicológico sobre a entrevista em pesquisa. In: SZYMANSKI, H.; ALMEIDA, L. R.; PRANDINI, R. C. A. R. (org.). A entrevista na pesquisa em educação: a prática reflexiva. Brasília: Plano, 2002.

SZYMANSKI, H.; SZYMANSKI, L. O encontro reflexivo como prática psicoeducativa: uma perspectiva fenomenológica. Revista de Educação, Ciência e Cultura, v. 19, n. 1, p. 9-22, 2014.

SZYMANSKI, H.; SZYMANSKI, L. Repercussões do pensamento fenomenológico nas práticas psicoeducativas. In: BARRETO, C. L. B. T.; MORATO, H. T. P.; CALDAS, M. T. (org.). Prática psicológica na perspectiva fenomenológica. Curitiba: Juruá, 2013.

SZYMANSKI et al. A transição do ensino infantil para o ensino fundamental no olhar das crianças, pais e educadores: um recorte fenomenológico. Revista de Educação PUC-

Campinas, vol. 16 n. 2, p. 147-153, 2011.

THIOLLENT, Michel. Notas para o debate sobre pesquisa-ação. In: BRANDÃO, C. R. (org.). Repensando a pesquisa participante. São Paulo: Brasiliense, 1999.

ZITKOSKI, Jaime José. Diálogo e dialogicidade. In: STRECK, D. R.; REDIN, E.;

ZITKOSKI, J. J. Dicionário Paulo Freire. Belo Horizonte: Autêntica, 2010.

Data de recebimento: 06/05/2015

Data de aceite: $15 / 02 / 2016$ 